\title{
Sedimentary derivatives of green sulphur bacteria as a molecular proxy for the assessment of euxinic conditions in the photic zone
}

\author{
J. S. Sinninghe Damsté
}

Netherlands Institute for Sea Research, Department of Marine Biogeochemistry and Toxicology, PO Box 59, 1790 AB Den Burg,

The Netherlands

Organic matter burried in sediments contains a multitude of palaeoceanographic and palaeoclimatic signals. With the major developments in instrumental analytical chemistry in the last 20 years, the decoding of these signals has become possible and molecular fossils have become an important tool in the assessment of palaeoenvironments. For instance, the determination of the number of double bonds in sedimentary long-chain ketones derived from coccolithophorid algae is now a widely applied technique in palaeoceanography to determine past sea-surface temperatures (Brassell, 1993). In this paper we will demonstrate the use of molecular fossils derived from the carotenoid isorenieratene to assess photic zone euxinia in ancient depositional environments. As an example the redox state of the North Atlantic Ocean during the Cenomanian/Turonian $(\mathrm{C} / \mathrm{T})$ anoxic event will be evaluated.

\section{Results and discussion}

Photosynthetic green sulphur bacteria (Chlorobiaceae) are photoautotrophic organisms that are strictly anaerobic and require hydrogen sulphide. Their presence points to an euxinic water layer that reaches into the photic zone. Chlorobiaceae produce a characteristic pigment, the diaromatic carotenoid isorenieratene I, which can be used to trace such conditions. For example, in the recent Black Sea, Repeta et al. (1989) isolated isorenieratene from water samples at $80 \mathrm{~m}$ from the surface, indicating the coexistence of light and hydrogen sulphide at this depth. Recognition of photic zone euxinia in past depositional environments is, however, hampered by the various transformation reactions occurring with isorenieratene during diaand catagenesis. We have discovered a wide range of diagenetic products of isorenieratene in rock samples from different geographical locations throughout the Phanerozoic which will be briefly discussed. Their identification was confirmed by their enriched $\delta^{13} \mathrm{C}$ values, which relate to the biosynthesis of
Chlorobiaceae via the reversed TCA-cycle. The diagenetically related $\mathrm{C}_{40}$ diaryl isoprenoid isorenieratane II and other derivatives (e.g. III-V), which have been found in several recent and ancient sediments (e.g. Sinninghe Damsté and Koopmans, 1997), are therefore excellent palaeoenvironmental indicator for 'photic zone euxinia'. The occurrence of isorenieratene derivatives in recent marine sediments is restricted to those of the Black Sea (Sinninghe Damsté et al., 1993). They are not present in sediments below intense oxygen minimum zones, such as those in the Arabian Sea or Peru upwelling region. Furthermore, they were also not identified in the recent sediments of the euxinic Cariaco Basin
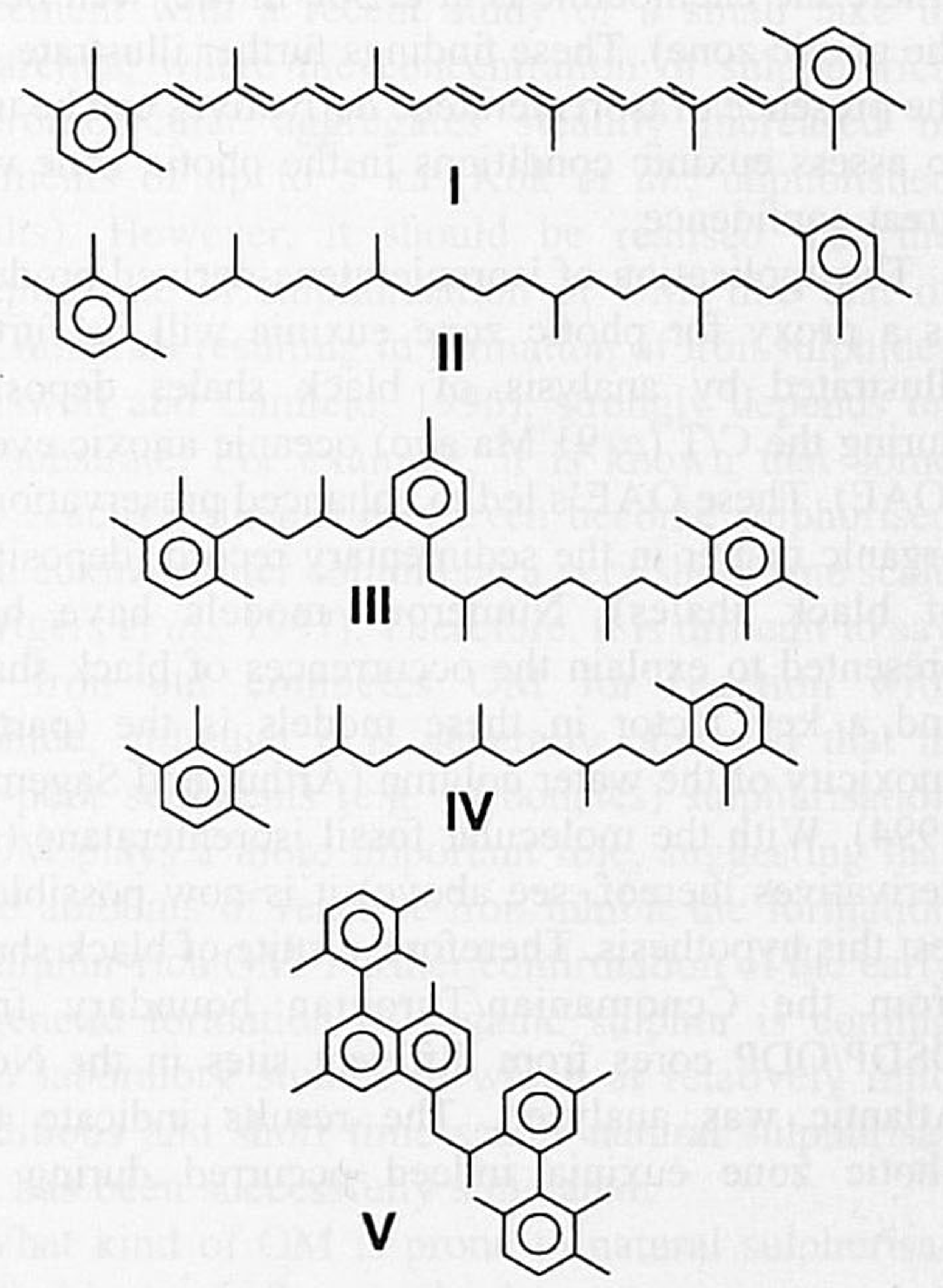

FIG. 1. Structures of isorenieratene (I) and some of its diagenetic derivatives (II-V) occurring in sediments. 


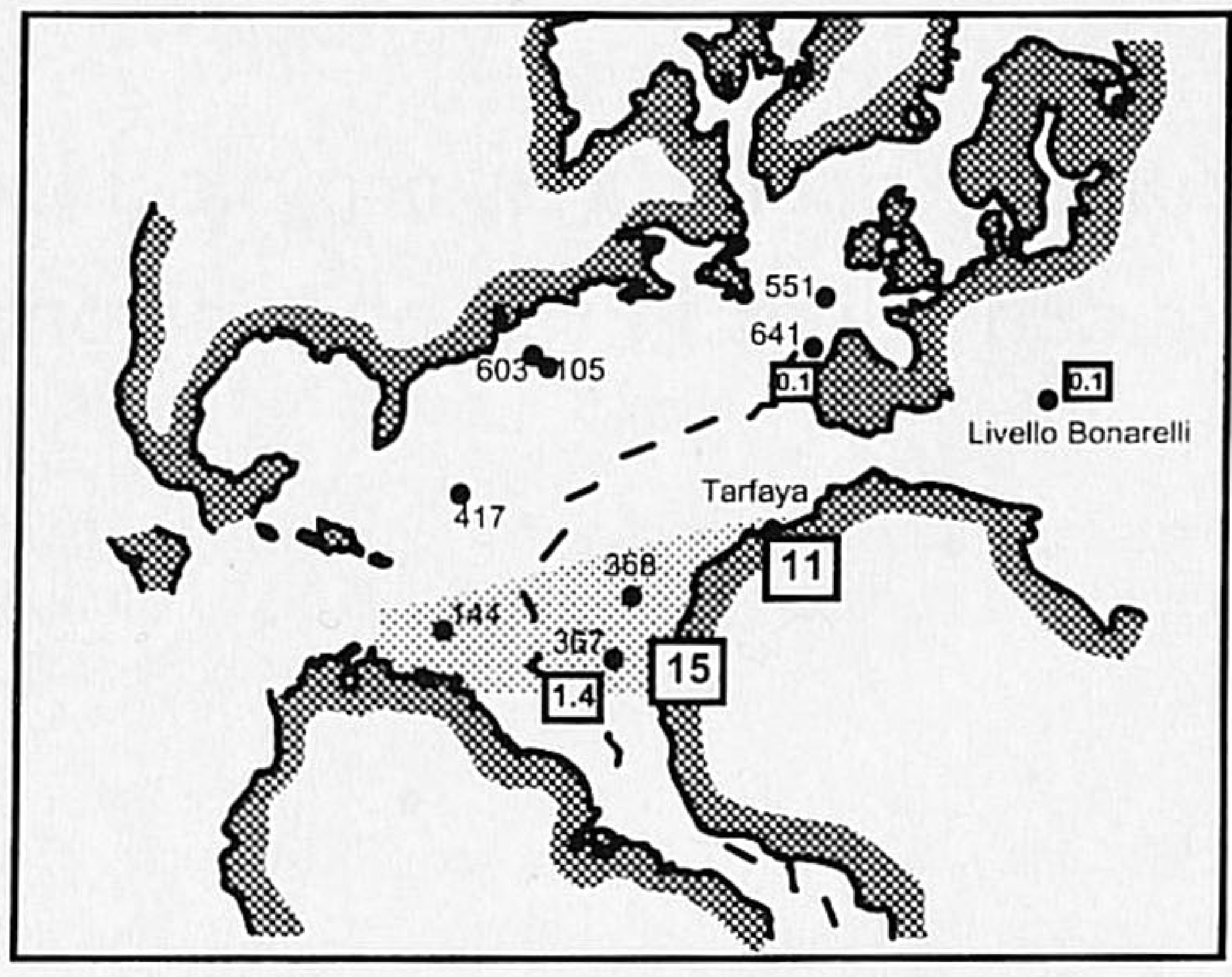

FIG. 2. Palaeogeograpical map of the North Atlantic Ocean during $\mathrm{C} / \mathrm{T}$ times with the investigated sites indicated with closed circles. Numbers refer to DSDP/ ODP sites. The stippled line indicates the mid-oceanic ridge. $\mathrm{C} / \mathrm{T}$ black shales from sites in the shaded area between the South American and African continental plates contain isorenieratene derivatives, indicating photic zone euxinia. The numbers in boxes indicate the $C_{\text {org }}$ accumulation rates in $\mathrm{gC} \mathrm{m}^{-2} \mathrm{y}^{-1}$.

(Werne and Sinninghe Damsté, unpublished results), where the chemocline is at $c$. $300 \mathrm{~m}$ (i.e. well below the photic zone). These findings further illustrate that the presence of isorenieratene derivatives can be used to assess euxinic conditions in the photic zone with great confidence.

The application of isorenieratene-derived products as a proxy for photic zone euxinia will be further illustrated by analysis of black shales deposited during the $\mathrm{C} / \mathrm{T}$ (c. $91 \mathrm{Ma}$ ago) oceanic anoxic events (OAE). These OAE's led to enhanced preservation of organic matter in the sedimentary record (deposition of black shales). Numerous models have been presented to explain the occurrences of black shales and a key factor in these models is the (partial) anoxicity of the water column (Arthur and Sageman, 1994). With the molecular fossil isorenieratane (and derivatives thereof, see above) it is now possible to test this hypothesis. Therefore, a suite of black shales from the Cenomanian/Turonian boundary from DSDP/ODP cores from different sites in the North Atlantic was analysed. The results indicate that photic zone euxinia indeed occurred during the
Cenomanian/Turonian OAE but was restricted to the southern North Atlantic (palaeolatitude $0-15^{\circ} \mathrm{N}$ ). The presence of photic zone euxinia, together with evidence for bottom water anoxia and accumulation of redox-sensitive trace metals and hydrogen-rich organic matter, indicates a continuously euxinic water column. Concurrent with the high organic carbon accumulation rates, which are 15-150 times greater in the southern than in the northern North Atlantic, and the low biological productivity, this suggests that preservation rather than production controlled the accumulation of organic carbon in $\mathrm{C} / \mathrm{T}$ black shales.

In addition to their presence in $\mathrm{C} / \mathrm{T}$ sediments, isorenieratene derivatives have been found in numerous other marine, organic matter-rich sediments, indicating that photic zone euxinia has occurred much more widespread than we would expect on the basis of its present-day occurrence. Notable examples include the eastern basin of the Mediterranean during Pliocene sapropel formation, the Jurassic Kimmeridge Clay Formation, Toarcian black shales deposited in Western Europe and the Western Canada Basin during the Devonian.

\section{Conclusion}

The presence of isorenieratene derivatives in sediments is a useful proxy for the assessment of euxinic conditions in the photic zone in both deep and shallow (e.g. epicontinental basins) water environments.

\section{References}

Arthur, M.A. and Sageman, B.B. (1994) Annu. Rev. Earth Planet. Sci., 22, 499-551.

Brassell, S.C. (1993) In: Organic Geochemistry: Principles and Applications (M.H. Engel and S.A. Macko, eds.). Plenum, New York, pp 699-738.

Repeta, D.J., Simpson, D.J., Jørgensen, B.B. and Jannasch, H.W. (1989) Nature, 342, 69-72.

Sinninghe Damsté, J.S., Wakeham, S.G., Kohnen, M.E.L., Hayes, J.M. and de Leeuw, J.W. (1993) Nature, 362, 827-9.

Sinninghe Damsté, J.S. and Koopmans, M.P. (1997) The fate of carotenoids in sediments: An overview. Pure Appl. Chem., 69, 2067-74. 